\title{
Lights Off, Spot On: Carbon Literacy Training Crossing Boundaries in the Television Industry
}

\author{
Wendy Chapple $^{1} \cdot$ Petra Molthan-Hill ${ }^{1}\left[\right.$ Rachel Welton $^{1} \cdot$ Michael Hewitt $^{1}$
}

Received: 13 April 2018 / Accepted: 13 November 2019 / Published online: 5 December 2019

(c) The Author(s) 2019

\begin{abstract}
Proclaimed the "greenest television programme in the world," the award-winning soap opera Coronation Street is seen as an industry success story. This paper explores how the integration of carbon literacy training (CLT) led to a widespread transformational change of practice within Coronation Street. Using the theoretical lens of Communities of Practice (CoP), this study examines the nature of social learning and the enablers and barriers to change within the organization. Specifically, how boundary spanning practices, objects and people led to the transformation on both a personal and group level. Based on a qualitative analysis of 22 interviews with Heads of Departments and other staff, the paper argues that CLT is a boundary practice which has evolved into a boundary spanning CoP. The importance of infrastructures supporting boundary objects and practices is highlighted as reinforcers of the CLT, both as a boundary object and a community, with the "ultimate" boundary spanning object being the show. A significant enabler in social learning and change in practice is the creation of discursive and creative space, both within CoP and across the boundaries. Findings also highlight the role of "self" in the process of social learning and organizational change. Distinct patterns emerged in the relationship between self-identity, social learning and change across a range of boundary objects, practices and communities both in the CLT and CoP. This suggests that in a diverse social learning setting such as CLT there are different transformational catalysts within the CoP and these identities can influence how knowledge is translated into practice.
\end{abstract}

Keywords Carbon literacy $\cdot$ Responsible management education $\cdot$ Communities of practice $\cdot$ Social learning $\cdot$ Boundary practice $\cdot$ Boundary objects · Boundary spanners

Electronic supplementary material The online version of this article (https://doi.org/10.1007/s10551-019-04363-w) contains supplementary material, which is available to authorized users.

Petra Molthan-Hill

petra.molthan-hill@ntu.ac.uk

Wendy Chapple

wendy.chapple@ntu.ac.uk

Rachel Welton

rachel.welton@ntu.ac.uk

Michael Hewitt

michael.hewitt@ntu.ac.uk

1 Nottingham Business School, Nottingham Trent University, 50 Shakespeare Street, Nottingham NG 1 4FQ, UK

\section{Introduction}

Coronation Street, produced by ITV in Manchester UK, is one of the longest running soap operas. It is a much-loved British institution reflecting the daily lives of a workingclass community in the North of England. First aired in 1960 (BBC 2010), it currently transmits six times per week with an average of 8.1 million viewers per episode, making it the most watched continuous drama on UK television (Broadcasters' Audience Research Board 2018). Coronation Street has acquired the accolade of the "greenest soap opera in the world," making the show an industry sustainability success story (Manchester Evening News 2015). This paper aims to explore how an industry focussed Carbon Literacy Training (CLT) program acted as a catalyst for this change within Coronation Street by assessing the impacts of the CLT on individual Heads of Department (HoD) and exploring the process of social learning, translation and adaptation of practice within and across departments. 
Coronation Street was one of the first production units within ITV to ask all their Head of Departments (Editorial, Production and Post Production) to take part in the newly developed CLT program which resulted in an overall reduction of carbon emissions of 96 tonnes between 2014 and 2016. The show's success has also been an inspiration to others in the sector: two of the other "top 3" soap operas in the UK, EastEnders and Emmerdale, have followed suit and also undertaken the CLT program. All three soap operas have achieved Albert certification, a certificate awarded by the British Academy of Film and Television Arts (BAFTA 2017) for successful Greenhouse Gas Management.

Within the responsible management education literature, there have been discussions regarding the barriers to change and transformation, particularly in the context of Principles of Responsible Management Education (PRME) and Business School curricula (Solitander et al. 2012; Cornuel and Hommel 2015a; Rasche and Gilbert 2015; Millar and Price 2018). However, there has been relatively less work assessing responsible management learning within the workplace, resulting in a "skewed focus on responsible management education" (Laasch and Gherardi 2019, p. 2) and has led to calls for "a shift in emphasis of future research on responsible management and responsible management learning" (Laasch and Gherardi 2019, p. 2). This research is answering this call by focussing on the process of responsible management learning and responsible management practice within a workplace setting with an exploration of factors that enable and influence this process of change.

In the literature it has been argued that successful learning within the workplace would enable employees to "make sense of the world and their place in it and instil in them a sense of responsibility for the common good" (Dyllick 2015, p. 21). Thus learning is used to provide knowledge and inform meaning within the working environment which can lead to responsible management where "practices of managing responsibly is characterized by deeply embedding sustainability, responsibility and ethics into every manager's work" (Laasch and Conaway 2015, p. 25). To do this requires a sense of situated responsibility and practice, embodied by the manager as a whole person (Laasch and Gherardi 2019).

By focussing on practice and the mechanisms for changing management practice, we are shifting from the ontological question of what managing responsibly is, to an ontoepistemological one of how managing responsibly is done and how it becomes situated in practice (Gherardi 2019; Price et al. 2019). This recognises explicitly that managing responsibly is co-constructed and emergent within a "texture of practice" (Gherardi 2006, p. 55), in other words it is part of the surrounding and interacting practices in a specific site (Price et al. 2019, p. 2). This suggests that a practice-based approach is required to understand the interconnections and mechanisms for the co-construction of responsible management practice.

According to Price et al. (2019) and Gherardi (2019), by focussing on a practice-based approach, four principles come into play. First is situatedness, in situ practice and interconnectedness; it is important to assess how practice brings together humans, non-humans, tools, technologies, rules and discourses and how practices happen and are interconnected with other practices (Price et al. 2019; Gherardi 2019). Second, situated collective knowledge, or collective "doing" which is "socially recognised and collectively sustained" (Price et al. 2019, p. 6). Third is the co-existence of managing responsibly with other practices and understanding the interconnections in practice across boundaries (Price et al. 2019; Gherardi 2019). The fourth principle is agencement, (agency) which is emergent when elements (human and non-human) achieve agency from being connected to other elements (Price et al. 2019; Gherardi 2019).

Pelling et al. (2008) suggest that learning in the workplace can result in changes to agency and can involve formal and informal allegiances (human) and actants (non-human) and can result in system change via changes in processes and practice (Pelling et al. 2008; Dyball et al. 2007; Keen et al. 2005). This is advanced by Pelling et al. (2008) who suggest that the individual and collective actions within organizations influence the processes which, in the context of this study, could be a training intervention such as CLT and the process of translation into departments. Pelling and High (2005) extend this to focus on 'material adaptation' and 'institutional modification' as valid adaptive strategies and, beyond this, how the learners learn; Bateson (2000) termed this 'deutero-learning', learning to be adaptive.

This paper aims to explore this process of transformational learning and adaptive processes towards responsible management practice within Coronation Street. In particular, we focus on the role CLT has within Coronation Street in changing both individual and collective processes and actions through social learning within the organization. We trace through the initial impact on the individual managers and explore if, and how, this learning was translated and adapted to become embedded within departmental processes and practices. This mapping of the impact of CLT is important and has the potential to make a significant contribution to the literature on both responsible management and responsible management education and learning in three ways:

(i) The paper examines sector specific training delivered in the workplace, enabling an exploration of the inter-relationship between the training course and organizational change. Some academics have postulated that purely academic approaches involving the transmission of theories, facts and figures 
are unlikely to be successful in bringing change in responsible management behaviour (Ackoff and Greenberg 2008; Cornuel and Hommel 2015b; Dyllick 2015; Pless et al. 2011). There needs to be a combination of transformative learning, issue-centred future relevant learning and reflective practice (Muff et al. 2013). This research assesses if, and how, CLT delivers transformational learning and how this knowledge is subsequently translated into workplace practice.

(ii) Patterns emerged during the research between the individuals' self-identity and prior identification with climate change and the nature of catalysts for change within the CLT and workplace. The notion of self-identity and engagement has been highlighted as important in the social learning and responsible management education literatures but has been relatively under-explored in the workplace setting. Shrivastava (2010) argues the importance of developing a passion for sustainability, whilst Hibbert and Cunliffe (2015, p. 180) argue that there needs to be moral reflexive process, which is "a means of interrogating our taken-for-granted experience by questioning our relationship with our social world." Cunliffe (2009, p. 94) argued that this reflexive process needs to be connected to threshold concepts which are "transformational within learning and practice," in other words catalysts that lead to "ethical and moral action are embedded in a relational understanding, enacted through self- and critical-reflexivity." This study provides insights on how self-identity shapes what threshold concepts are, and the nature of relational understanding and associated actions of managers within their departments.

(iii) This research explores how identity and the nature of belonging to a group influences the nature and process of translation, adaptation and embedding sustainability within group practice and process. In understanding the relationship between the nature of belonging to a group and how social learning manifests informs responsible management processes both within groups and at organizational level (Pelling et al. 2008).

This paper uses the lens of Community of Practice (CoP) (Wenger 1998) to explore how the CLT directly influences individual managers and to assess how the CLT knowledge and experience was translated, adopted and adapted within different communities of practice at Coronation Street. This theoretical lens allows us not only to understand the social dynamics within the various communities and groups, but also the dynamics and learning spaces between groups. An important element in understanding the social learning dynamics is the notion of a boundary between $\mathrm{CoP}$ and how practices, people and objects enable social learning between communities that lead to adaption and adoption of sustainability practices within the various CoP. In this paper, CLT initially is conceptualized as a boundary practice, however we see other boundary practices, objects and ultimately a $\mathrm{CoP}$ emerges to reinforce CLT as a practice and enables further learning to take place within and across different $\mathrm{CoPs}$ in Coronation Street. Hence, the social learning becomes "organic" and "locally owned" within the organization. The interactions between boundary practices, objects and people are explored to understand how sustainability is being embedded within the ultimate boundary object: the show. By doing so, one can start to understand the factors that led to successful organization-wide change in sustainability practice within Coronation Street and the implications for other organizations.

The CLT program is an interesting case to study and to explore for a number of reasons. First, the CLT program (a boundary practice), is designed as a social learning experience with participants drawn from a number of different and distinct CoP within Coronation Street. This provides an opportunity to explore how social learning takes place across distinct boundaries, both during and after the CLT course. This enables a deeper understanding of catalysts for change in practice and the use of objects, practice and people in the translation of sustainability-related practice both between and within departments. This further leads to significant insight into how new boundary practices emerge and develop. Secondly, within Coronation Street there is a very strong sense of culture and identity both at the organization level and within the CoP. This enables a deeper exploration into how identity and belonging influence the process of social learning and organizational change at multiple levels. This is particularly interesting in the Television Industry where there is a spectrum of technical and creative individuals and groups. Thirdly, at Coronation Street there is very clear focus and objective: the storyline and the show. The case provides opportunity to explore how CLT and sustainability-related boundary practices and objects influence, and are influenced, by the show.

This paper addresses the following two overarching research questions:

1. How has the CLT influenced social learning at both an individual and group level?

2. How has the knowledge gained from CLT been developed and translated into practice both within and across different communities of practice? What has enabled this process to take place? What are the roles of boundary spanners, boundary objects and boundary practices in the continued social learning and development of sustainability practices within and across groups? 
The paper is organized as follows: after a discussion of the relevant literatures on social learning and communities of practice (CoPs), boundary spanners, boundary objects and boundary practice the paper will apply the Gioia et al. (2013) methodology to this exploratory case study (Yin 2018). After an introduction to the background of CLT at Coronation Street the paper will present key findings as related to our research questions leading to a conceptualisation of the key findings and conclusions from the case.

\section{Literature Review}

The seminal work of Bandura (1978) introduced the notion of social learning, recognising that achievement of learning was in both formal and informal forms and was achieved by observing, conversing and through learning by doing. Bandura (1978) noted the focus of learning was the social interactions between the individual and the environment. As the field evolved, levels of analysis have moved beyond the individual to understand collective learning (Elkjaer 2001; Glasser 2007) drawing upon "divergent interests, norms, values and constructions of reality" (Wals 2007, p. 18). However, understanding how the individual interacts with, and learns from, social interactions is important, particularly in the context of assessing the impacts of CLT. Transformative social learning occurs when there is a disruption in individuals' own problematization of everyday events (Wals 2010) where mental models are reshaped and reorganized to take account of new information (Argyris and Schon 1996). However, for this to occur there needs to be space within the process for reflection, discussion and group problem solving (Wals 2007).

Individual identity within social learning is rather sparsely researched and theorised (Waitoller and Kozleski 2013). An individual's identity is continually evolving and combines the summation of previous experiences, personal history, future plans, hopes and ambitions. Wenger (2000) suggested that identities are crucial to social learning systems for three reasons. Firstly, identities combine a potent combination of competence and experience into a way of knowing. This is endorsed by Warr Pedersen (2017) who established that personal values and professional identity were the two driving factors for continued engagement in a collaborative peer-learning initiative. Identity can influence both the engagement in, and the form of, learning that takes place. Through the CoP lens, identity can also influence the nature of belonging to a community.

Secondly, identities play a role in how workers deal productively with boundaries by suspending or engaging identities (Wenger 2010). Learning in the workplace is not just an intellectual matter of translation (Green 2011), it involves individuals translating these practices across the boundaries into different contexts with identity shaping the understanding and recognition of social context (Lucas and Ogilvie 2006). Within the CLT context, the authenticity of the shared experience and the ability of the trainer to understand both the individual and collective identities of participants and activate them in different boundary groups all appear to be important factors in the success of social learning. Finally, identities are where boundaries are experienced in a personal way; a strong identity involves deep connections with others through shared histories, reciprocity, affection and mutual commitments, developing a process that builds bridges across communities. Emotional connectedness has been explored as a mechanism for developing collective identities (Hardy et al. 2005) where the combination of individual identity and collective identity leads to sustained action and impact (Warr Pedersen 2017).

To understand systems of social learning within groups and organizations, and particularly towards sustainability, there is an emergent body of work utilizing Wenger's (1998) CoP framework (Benn and Martin 2010; Benn et al. 2013). CoPs are the basic building blocks of the system (Wenger 1998) which are "social containers of competences" (Wenger 2000, p. 229) manifesting as loosely coupled networks driven by common interest (O'Donnell et al. 2003). Wenger (2000) defines learning within social learning systems as the interplay between social competence (being a competent member of a community of practice) and personal experience which emerges through mutual engagement, experience and participation (Lave and Wenger 1991). When successful, this can result in personal transformation alongside the evolution of social structures and associated practices to which the individual belongs.

CoPs are commonly recognised as having three elements: knowledge building, practice and community building (Wenger 1998). Gherardi (2009) argues that knowledge building needs to be situated in time and space within work practices to engender the building of knowledge "in situ" (Price et al. 2019; Gherardi 2019). The successful process of building knowledge requires energy for learning within the CoP which needs to be sustained by leaders (Wenger 2000). Practice, or "repertoire," tends to be tangible outputs of the group and could be development of tools, language and concepts which exemplify the community (Wenger 2000). Gherardi (2009, p. 352) argues that "situated, negotiated, emergent and embedded activity" embody knowledge within the CoP, therefore assessing these tangible outputs gives insight into how the CoP understands and evaluates practices and the collective knowledge in place (Price et al. 2019; Gherardi 2019). The final element of CoP, community, is the depth of social capital, cohesion and sense of common identity (Wenger 2000; O'Donnell et al. 2003). This sense of community and common identity is essential for the feeling 
of belonging to the group which can, in turn, influence the social learning process at individual and group level.

Belonging can involve one or a combination of three modes (Wenger 2000). The first, engagement, involves doing things together, talking and producing what he calls artefacts (e.g. problem solving, meetings). He argues that the level and mode of engagement can profoundly shape individual experience and identity. The second, imagination, involves the creation of image of self and community in order to orient, reflect and explore possibilities. It has a forward-looking orientation and, hence, uses tools and practices such as maps, strategy, scenarios and storytelling in order to understand and evaluate options. The final mode of belonging is alignment which involves a mutual process of co-ordinating perspectives and informs different ways of interpreting. This can encompass negotiating, moral codes and scientific process. The mode of belonging is important in understanding the social learning process within $\mathrm{CoPs}$ as it shapes both the nature of participation and how membership is experienced. Thus, membership of a CoP can impact all parts of members' lives (the double-knit process) where processes are investigated and integrated into both work and personal contexts (McDermott 1999). This can create a relational, interconnected and multidirectional learning loop (Smith et al. 2018).

The concept of boundaries between CoP is incredibly important from the social learning system perspective. Akkerman and Bakker (2011a, p. 133) state that a "boundary is seen as a sociocultural difference leading to discontinuity in action or interaction. Boundaries simultaneously suggest a sameness and a continuity in the sense that, within discontinuity, two or more sites are relevant to one another in a particular way" and Wenger (2000) suggests that shared practice by its nature involves boundaries. Boundaries are a key element in the study of social learning within organizations (Wenger 1998; Engeström et al. 1995) as they create 'spaces' for potential learning (Akkerman and Bakker 2011b). The source of difference can be in the form of purpose, histories, tools, objects, use of language, problem solving and interpretation but also can vary in terms of competences and capabilities embedded within different CoP. An important part of the social learning process is the translation of knowledge and practice at the boundary to enable interpretation and interaction between two or more CoP and these active boundary processes can be very organic and lead to higher learning and innovation potential within the system (Wenger 2000). Learning at the boundary takes place from "boundary crossing" (Engeström et al. 1995, p. 319) and involves a process of negotiation to combine activities and knowledge from different contexts to achieve a "hybrid situation." This can take the form of objects, practices or people. Wenger (2000) argues that these 'bridges' are important to enable these systems to work more tightly together.
Wenger (2000) defines boundary objects as objects which support connections between different practices in different $\mathrm{CoP}$ and classified into three categories. Firstly, artefacts which are tools, documents and models. Second, discourses, the existence of common language to enable communication and negotiation of meanings across boundaries. Third, processes, routines and procedures that allow multiple practices to coordinate. Briers and Chua (2001) add to the classification with a visionary boundary object classification which evokes positive emotional responses and holds high levels of legitimacy across CoP. These objects are introduced through boundary practices (Wenger 1998) where interpretation, adaptation and repurposing occur to enable objects to fit local needs and contexts (Barton and Tusting 2005). This involves the renegotiation of meaning (Ramsten and Säljö 2012) and can socialise the activities of users (Mäkitalo and Säljö 2002).

Bowker and Star (2000) argue that boundary objects and systems of boundary objects grow to become boundary infrastructures (Star 2010) due to information needs (Star and Griesemer 1989). According to Star and Ruhleder (1996) these infrastructures are embedded into other structures and go beyond one element of practice and link to the practice-based concept of interconnection (Price et al. 2019; Gherardi 2019). These are often shaped by CoP behaviours and are modified by and embody conventions and standards (Star and Ruhleder 1996) which are often learned as part of membership to a CoP (Star 2010; Lave and Wenger 1991).

Wenger (2000) defines boundary practices as spanning activities that become a sustained topic of practice of its own, crossing boundaries to create a bridge and establishing and sustaining interactions between $\mathrm{CoP}$ in an overarching practice (Coldren and Spillane 2007). This enables engagement and learning across CoP (Waitoller and Kozleski 2013) which can become routine (Coldren and Spillane 2007). Boundary practices often develop their own associated boundary objects however this is not necessarily always the case and might emerge as the result of the introduction of an object (Ramsten and Säljö 2012).

Wenger (2000) argues that CoP build their competences by participating in projects that combine the knowledge of multiple practices and, by doing so, combine application with capability development. This creates simultaneous learning loops or "double knot organizations" within which learning and innovation are synthesized and disseminated to CoP where knowledge is reworked and applied to new projects (McDermott 1999; cited in Wenger 2000).

Boundary Spanners are people who actively cross boundaries and are members of multiple CoP (Akkerman and Bakker 2011a; Wenger 2000). It is argued that successful boundary spanners have a special set of competences and thrive on working on the boundary. Wenger (2000) argues that they love connections between different communities and engage 
fully in the import and export of knowledge and practices. Boundary spanners contribute to boundary crossing through 'inbound processes' by introducing external repertoire into a community and outbound processes by enabling the movement of artefacts, people and their practices into new contexts. This requires a combination of knowledge, attitude and skills to cross boundaries (Karen and Bush 2010), which includes the ability to translate (Waitoller and Kozleski 2013) and the capacity for creating dialogue (Akkerman et al. 2006). Williams (2002) argues that boundary spanners are essentially acting as network managers who manage personal relationships and gain legitimacy within groups. This enables the mobilization of resources and effort through negotiation and brokering across boundaries. Often boundary spanners produce and use boundary objects which become locally useful and acquire a common identity (Levina and Vaast 2005).

Within the CoP literature, it has been shown that boundary practices, activities and objects can create and engender expanding discursive and creative spaces. Benn and Martin (2010) found that the utilization of boundary objects created social learning around sustainability through "opening and expanding a discursive space" (Benn and Martin 2010, p. 405). They also found that $\mathrm{CoP}$ and their boundary objects delivered social learning that was culturally relevant with implications for changing broader stakeholder practices as a result of this space. Applying Habermas' (1984) concept of 'lifeworld', O'Donnell et al. (2003) suggested creating a lifeworld setting within an organization through a CoP to open the space to explore new ideas, reflect on practice and develop new patterns of thinking and acting. They argue that when $\mathrm{CoP}$ are given space for communicative reasoning, the $\mathrm{CoP}$ can move beyond structural systemic influences freeing the creative potential of members and allowing the values to emerge. This might not just result in explicit knowledge that can be coded into mental schemes, but also knowledge acquired through the sensory and aesthetic pathways of employees in the working environment (Gherardi and Strati 2012). Therefore, CoPs can create discursive and creative space when they are given space for communicative reason and the ability to raise validity claims in order to create own meaning. As Wenger (1998) highlights there is a fine balance between giving space and organizational support: "Many are best left alone-some might actually wither under the institutional spotlight. And some may actually need to be carefully seeded and nurtured. But a good number will benefit from some attention, as long as this attention does not smother their self-organizing drive" (Wenger 1998, p. 7).

\section{Methodology}

Coronation Street is a single exploratory case study (Yin 2018) which utilises a social constructionist methodology informed by the Gioia systematic approach (Gioia et al.
2013) to unravel rich insights of such an empirical case. The research team had the opportunity to study the phenomenon of CLT within Coronation Street during 2017/2018. The Gioia process provides a process ensuring rigour and credibility (Meyer 2001). This allowed the examination of how Carbon Literacy Training has been effectively integrated in the management practices within the television industry.

The study was abductive in nature (Peirce 1931-1935) and supports the 'progressive extension of existing knowledge' (Gioia 2012, p. 15). The CLT within Coronation Street was seen as a 'puzzling observation' (Dubois and Gadde 2002; Spens and Kovács 2006) which enabled the exploration of the learning that ensued within the organization (Woodward 1989). Positioned in the field of responsible management education and social learning, the research was conducted with an open mind acknowledging the need to understand the social processes and how they manifest (Langley 1999) within and beyond CLT in Coronation Street.

\section{Data Collection}

An exploratory immersion within 'Coronation Street' was undertaken approximately a month before the main data collection (Järvensivu and Törnroos 2010). The purpose was to corroborate the suitability of the case study whilst ensuring it was appropriate for the project (Sandelowski 2010). In addition, this stage informed the approach by gaining familiarity with the organization and selecting the sample informants. CLT documents and materials were reviewed and notes taken. This informed the framing of questions surrounding the context and enabled exploration of some issues in greater depth during the interviews. In addition, the team were keen to give an authentic voice to the informants, recognising their roles as 'knowledgeable agents' and facilitating interviews to enable them to explain their thoughts, intentions and actions (Gioia 2012). These steps provided confidence that the case was likely to provide deep, locally constructed, contextual insights (Järvensivu and Törnroos 2010) and to provoke thought and new ideas (Siggelkow 2007).

Data collection included a mixture of key informant recorded interviews, document review and participant observation. The individual interviews were based on a semistructured interview schedule that focussed on (a) the CLT, for example which component of the training was most effective, (b) the impact of the training at an individual, departmental and organizational level and (c) individual attributes, e.g. background, role in the organization and knowledge, understanding and awareness of and views on carbon literacy before and after the training. The team explored how the CLT had impacted both the informants' work and personal life (Haugh and Talwar 2010), enabling us to explore how different individual perspectives influenced both engagement 
with the CLT and subsequent actions, and how organizational constructs influence their sense making (Gioia and Chittipeddi 1991) in terms of reducing carbon emissions and broader sustainability issues.

A convenience sample of key informants $(n=22)$ included HoD in Editorial and Production, Script Writers and an actor from a range of departments across the organizations involved. The actors in Coronation Street did not participate in the CLT program, however an actor's perspective was included to gauge the broader perceived impact of CLT on the show. Table 1 summarises the roles and levels of the informants. A potential limitation is that only partial demographic data was collected on each informant. For instance, political allegiance was not collected and, in this respect, the sample could therefore be biased in some way. In the US and in Western European countries there is a well-documented association between climate change beliefs and broad political affiliation; citizens on the left of the political divide reporting stronger belief in climate change and support for action to mitigate it than citizens on the right (McCright et al. 2016). The findings from this study illustrate that, collectively, the informants revealed a wide range of positions on climate change scepticism pre-CLT and, hence, we surmise that our sample was not obviously biased with respect to any one broad view of climate change.

The findings section includes anonymized quotes to illustrate the identified themes (see supplementary data table). Each quote is referenced by a preassigned informant ID number to indicate the source and role e.g. Production Technical 2. Quotes that included references to future storylines in the programme have been appropriately redacted to protect confidentiality and commercial interests.

The interviews were conducted together by two of the authors. This approach ensured that McNamara's (2009) interviewing principles were adopted, ensuring interviews covered all the topics in the timeframe given and were objective in lines of enquiry. The interviews lasted approximately one hour and were held between November 2017 and March 2018. They were digitally recorded and initial notes and observations were made immediately after the interviews. This step in the process authenticates that interviewing and analysis were concurrent processes (Langley 1999; Locke and Golden-Biddle 1997; Lincoln et al. 2011). Recordings of the interviews were transcribed verbatim, allowing the informants to focus upon the questioning and to enable the use of direct quotes in subsequent analysis. The research gained institutional research ethics approval and followed associated guidelines.

\section{Analysis Strategy}

Using the Gioia et al.'s (2013) approach, a first and second order analysis was undertaken. The first order analysis was conducted by two members of the research team to overcome any biases and allowing for discovery without prejudicial assumptions. The first order open coding was conducted taking guidance from Strauss and Corbin's (1998) protocols, using the informants' terms and making little endeavour to filter down the codes in order to understand the phenomena, rather than to construct the data set to fit within preconceived theoretical categories. At a pivotal stage the themes emerged as represented in Fig. 1 and provided a compelling data structure to shape and demonstrate the rigour of the analysis (Pratt 2008; Tracy 2010).

The second order analysis was conducted to help to explain how the CLT has prompted the embedding of sustainability practices at Coronation Street. This dynamic theoretical stage allowed the exploration of emerging themes manifesting from the data and challenge where there were unexpected omissions when the researchers returned to the existing responsible management education, social learning and CoP literature. As the tentative relationships started to emerge, a creative iterative process followed that resulted in the categories in the second order process (see Fig. 2). This demonstrates the 'systematic combining' of data to theory (Dubois and Gadde 2002) to facilitate a new framework to the phenomenon (Kirkeby 1990), a key stage of the abductive approach.

Table 1 Summary of key informants

\begin{tabular}{lcl}
\hline Type & Number & Example roles and level within the organisations \\
\hline CLT leader/production & 6 & Management levels roles within a Community Interest Company and at ITV and BBC \\
Production creative & 6 & $\begin{array}{l}\text { Heads of Department, supervisors and assistants in various departments including } \\
\text { costume, story line and design }\end{array}$ \\
Production technical & 6 & Heads of Department and managers in technical areas such as cameras and sound \\
Creative show & 1 & Actor \\
Support services & 3 & Catering staff including supervisory role \\
Total & 22 &
\end{tabular}


First Order Concepts

\begin{tabular}{|c|}
\hline Personal values \\
\hline Self identity \\
\hline
\end{tabular}

Pre-existing climate change knowledge

Pre-exisiting sustainability practice

\begin{tabular}{|c|}
\hline CLT alignment to values \\
\hline CLT linkage to role \\
\hline
\end{tabular}

CLT peer to peer learning

\begin{tabular}{|c|}
\hline CLT enabling \\
\hline CLT empowerment \\
\hline CLT commitment \\
\hline
\end{tabular}

\begin{tabular}{|c|}
\hline CLT knowledge \\
\hline CLT triggers \\
\hline CLT catalyst \\
\hline
\end{tabular}

Modes of collective decision making

\begin{tabular}{|c|}
\hline making \\
\hline Belonging to group \\
\hline Social movement \\
\hline $\begin{array}{c}\text { Peer-peer interaction and } \\
\text { influence in group }\end{array}$ \\
\hline
\end{tabular}

\begin{tabular}{|c|}
\hline Group problem Solving \\
\hline $\begin{array}{c}\text { Translation of individual } \\
\text { knowledge in group }\end{array}$ \\
\hline $\begin{array}{c}\text { Social influence from outside } \\
\text { group }\end{array}$ \\
\hline "Reflection of society" \\
\hline
\end{tabular}

\section{Data Structure}

Second Order Concepts

\section{Aggregate Dimensions}

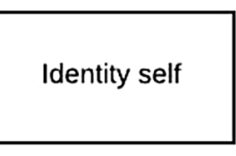

Climate change self
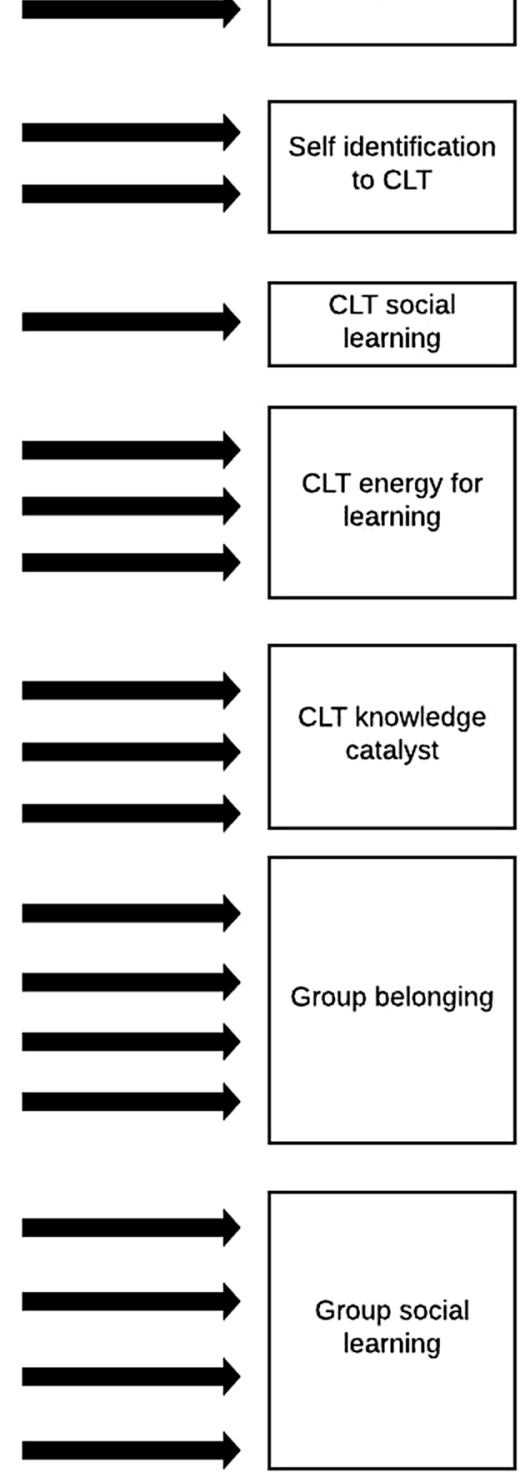

CLT

Individual Impact

Within group social learning

Fig. 1 1st and 2nd order analysis: coronation street interviewee codes and categories

\section{Analysis and Discussion}

To contextualise our findings, we first provide an introduction to the Coronation Street case study with background information on the Coronation Street production unit and how the CLT was designed and delivered. 
Data Structure

(continued 2)

First Order Concepts

\begin{tabular}{|c|}
\hline Sustainability related objects \\
\hline New building \\
\hline Resources \\
\hline
\end{tabular}

\begin{tabular}{|c|}
\hline Engagement \\
\hline Empowerment \\
\hline Challenge \\
\hline \hline "Doing better" \\
\hline Enabled \\
\hline
\end{tabular}

\begin{tabular}{|c|}
\hline Control \\
\hline Voice \\
\hline Space \\
\hline
\end{tabular}

\begin{tabular}{|c|}
\hline Creativity \\
\hline Innovation \\
\hline
\end{tabular}

\begin{tabular}{|c|}
\hline Budgets and resources \\
\hline Scripts and storyline \\
\hline Albert related processes \\
\hline
\end{tabular}

\begin{tabular}{|c|}
\hline $\begin{array}{c}\text { Individuals who influenced } \\
\text { across groups }\end{array}$ \\
\hline $\begin{array}{c}\text { Individuals who moved } \\
\text { between groups }\end{array}$ \\
\hline
\end{tabular}

\begin{tabular}{|c|}
\hline Storyline meetings \\
\hline Production meeting \\
\hline Environment committee \\
\hline
\end{tabular}
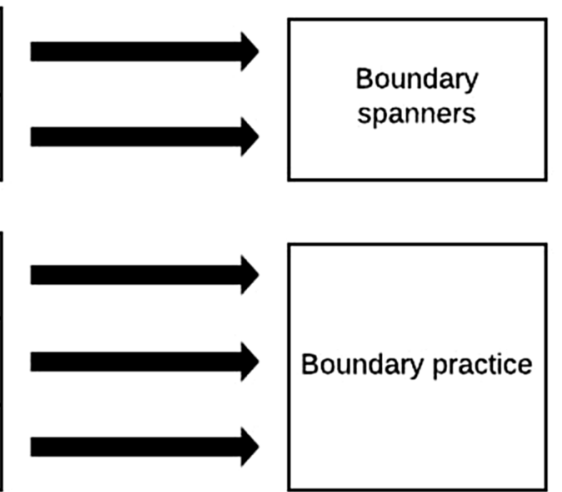
learning and
Second Order Concepts

Visibility of sustainability objects

Energy for change

Space for translation

Creative mindset

Boundary objects

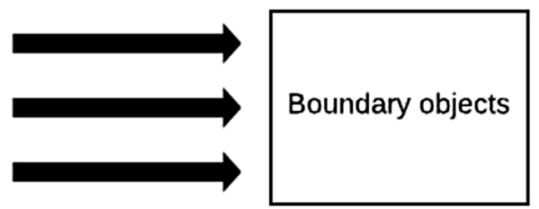

Within

group

change

process

Boundary

work

between

groups

Fig. 1 (continued)

\section{Carbon Literacy Training Background}

CLT as practised in Coronation Street and therefore in this paper, is based on the definition given by Cooler Project CIC in their Carbon Literacy Standard (2016, p. 1): "An awareness of the carbon dioxide costs and impacts of everyday activities and the ability and motivation to reduce emissions on an individual, community and organizational basis." The 
Data Structure

(continued 3)

First Order Concepts
Second Order Concepts
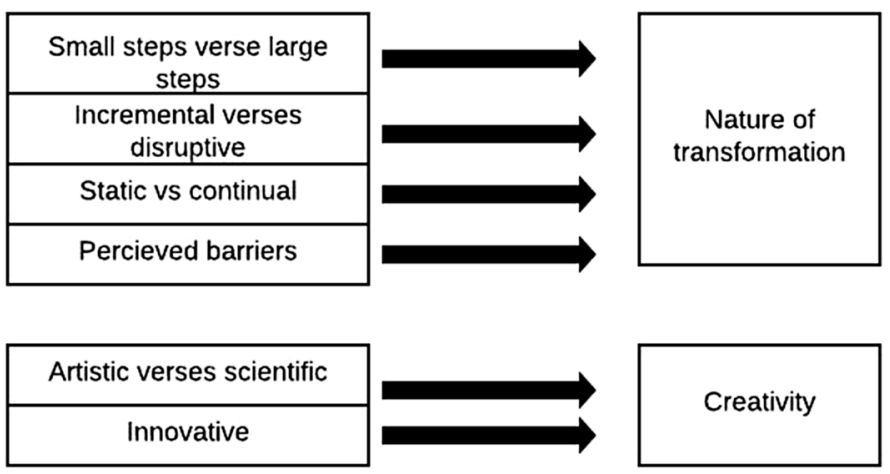

\begin{tabular}{|c|}
\hline Second nature \\
\hline Adoption \\
\hline Adaption \\
\hline "Always done it this way" \\
\hline Embedded \\
\hline
\end{tabular}
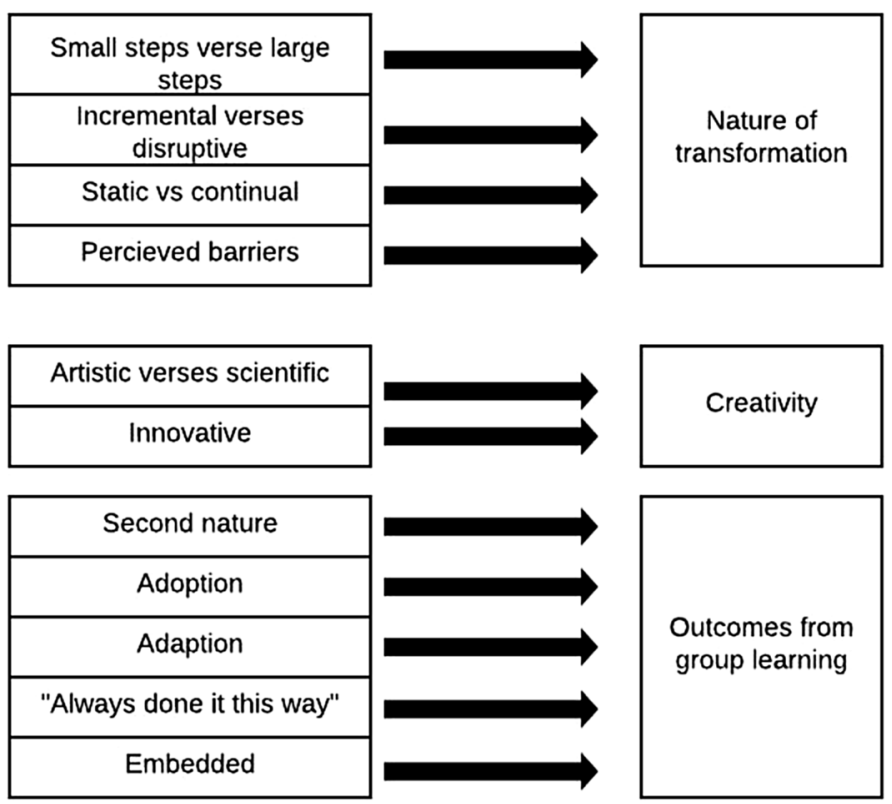

Aggregate Dimensions

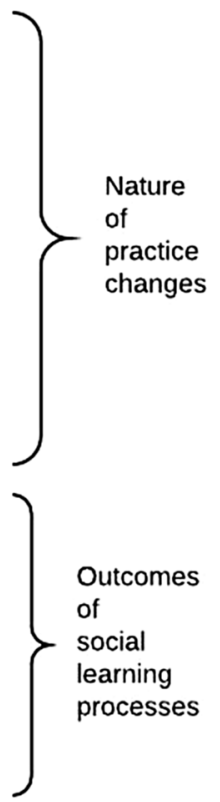

Fig. 1 (continued)

Carbon Literacy Project (2011, and Carbon Literacy Standard 2016) developed by Cooler Projects CIC (2011) was recognised as being globally unique at the Paris Climate Summit in 2015 and has been listed as a Transformative Action Program.

The CLT at Coronation Street was designed in a partnership between Cooler Project, BBC North and ITV. One of the principles of the Carbon Literacy standard is peer-topeer learning and social learning by design, meaning the creators of the training were from the same background, familiar with the creative industries and, more specifically, with the work within a production unit. A specific pedagogy was applied, introducing the science in a very accessible way using storytelling, games, role playing and quizzes which is consistent with the predominant cultures and narratives within the television industry. These were adapted to the dominant areas of practice (production, editorial, leadership) with the clear aim to achieve changes in practice through the use of pledges. The CLT programme was championed by a Senior Production Manager within Coronation Street who was also involved in the design. This manager negotiated across both Coronation Street and ITV to gain support and buy-in for the training and, as a result, the CLT training was compulsory for the HoD within Coronation Street. Despite the compulsory nature of the training, the HoD were left to their own initiative as to how they wanted to implement the training within their departments. However, the Senior
Production Manager would hold regular meetings with the HoD to evaluate progress being made and problems being encountered.

The training was delivered by someone who had a television background but was external to Coronation Street; this enabled them to both understand the challenges a production unit faces and provide legitimacy to the participants. The training was designed to fit within the culture of television industry which traditionally rejects anything perceived as "too corporate." Within the CLT cohorts there was a mix of participants from different departments, however, there was a differentiation made between CLT for production, editorial, leader, producer, and technologists. For example, in the Production-CLT there was a mix of departments, including the more technical departments such as sound, lighting and transport, but also the more creative departments such as costumes and props.

Throughout, the CLT informants were encouraged to reflect on climate change and how it was linked to their individual values and personal identity and, more importantly, tied to commitment and action both at an individual level and in their professional roles. The trainer prompted the group to create a proactive mind-set of shared targets and tentatively suggested common values that the group could adopt to make improvements both on a personal and collective level. The participants were encouraged to design an action plan which outlined the next steps their team could 


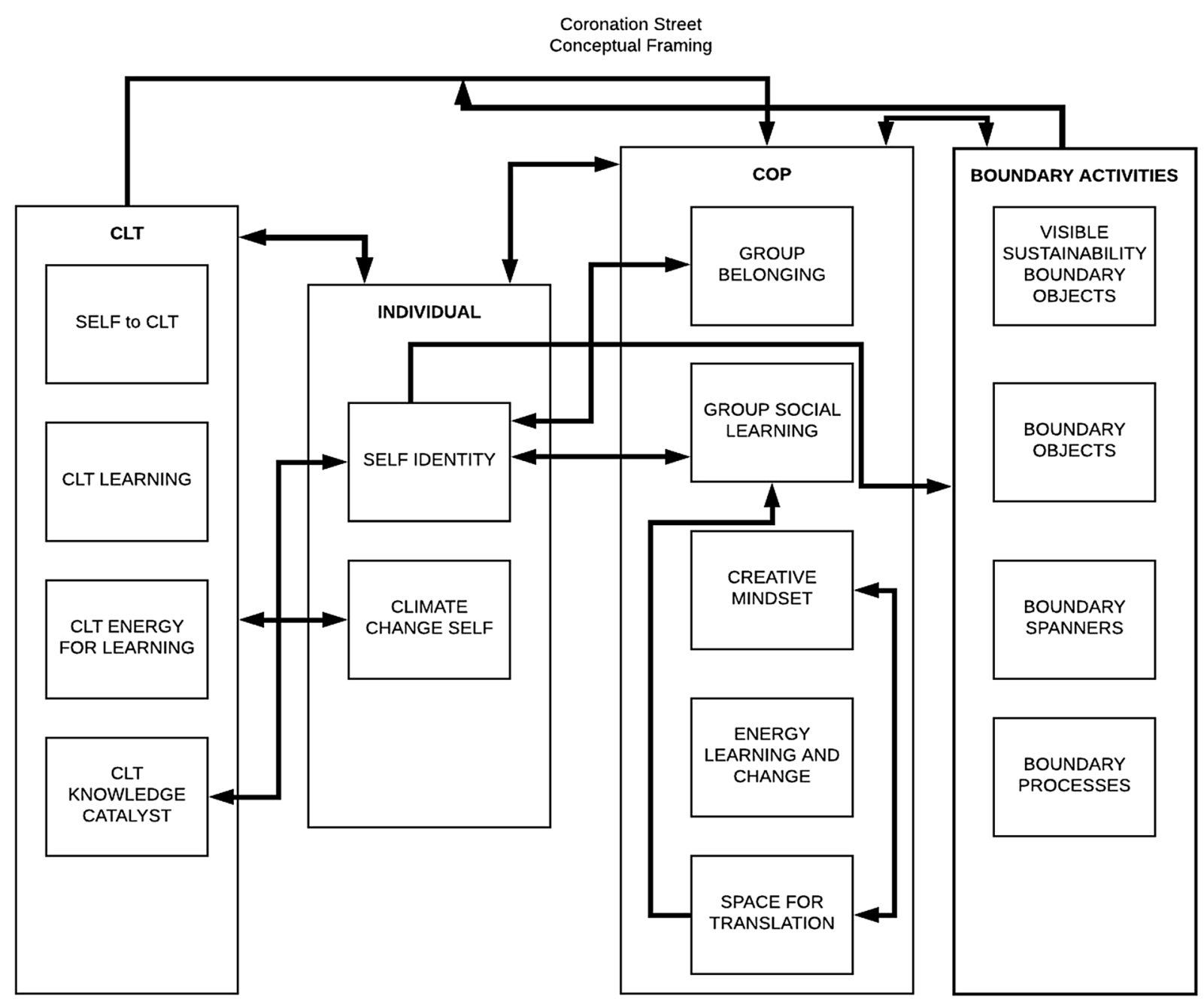

Fig. 2 Second order themes and related theoretical concepts

take. Each participant also formulated a personal commitment in the form of a pledge and, on completion of the training, they received a Carbon Literacy Certificate 2017 issued by Cooler Projects.

\section{How has CLT Influenced Social Learning at an Individual Level and at Group Level?}

Identity captures past experiences, learning, competence and perception of self but also contains future hopes, plans and ambition (Wenger 2000). Identity not only shapes the nature of engagement with social learning within $\mathrm{CoP}$ but is also shaped by the participation within the CoP (Lucas and Ogilvie 2006). In other words, this is where the individual learning outcomes from CoP participation reside, both in terms of identity within the group "becoming the expert on..." but also in broader self-identity (Lave and Wenger 1991).

In Coronation Street the framing of self-identity influenced how participants engaged in and learned from CLT training and how they translated this knowledge into practice within their respective CoPs (Wenger 2000; O'Donnell et al. 2003). There were two distinct clusters; those that classified themselves as "scientists" or "techie" and those that identified themselves as "creative" and "artistic." Those self-identified as "scientists" tended to be more evidencebased when discussing and engaging with climate change and sustainability, both within Coronation Street and in the broader world context. They were also inclined to identify as "sceptical" and more strongly highlight the barriers to change. Within their CoPs, they tended towards more technical adaptations and evidence-based solutions often framed within technical boundaries.

Those individuals who identified as "artistic" or "creative" tended to be less evidence-based but more values driven in their engagement with CLT and CoPs. Rather than seeing barriers, they saw a "challenge" which acted as catalyst for creative solutions both at an individual level and within their respective CoPs. 
Identity also shaped attitude and perception of climate change as an issue. All those who self-identified as being artistic saw climate change as an opportunity whilst those who identified themselves as "scientific" varied between opportunity or threat. All informants had prior knowledge of climate change to varying degrees, although none would identify themselves as "Carbon Literate" before the training. Some of the informants exhibited more deeply rooted environmental embeddedness within their identities:

...this is me in my life, mend, reuse or recycle. Creative Show (1).

I probably always have been very open to it and environmentally aware and it probably comes from my background as well. My mum was an avid Greenpeace supporter and campaigner so I think, subconsciously, it's always been there. Production Creative (2)

...when I started to look into where things came from I was like, I don't agree with this at all. So then I started to change my vote with my pound, basically, so it started with not buying anything that was tested on animals Production Creative (3).

...there is always the sceptical side it's not happening, it's isn't... you know those angles anyway... I think it is quite interesting to know the arguments for and against and see how the swingometer swings. Production Technical (2).

The course itself created a social learning space across CoP, and hence it is a boundary practice, with the course content/ notes being boundary objects that are taken back into $\mathrm{CoP}$. As Wenger (2000) states central to the learning at the boundary is the experience and engagement of the individual. This was embedded within the CLT design:

There is a lot in there so it is definitely NOT 'this is climate change, here's another Polar Bear' and it's not just a manual of how to play with your thermostat. It is all of that with the essential wrapping of social learning throughout. So it starts with you, us, and making it relevant from the off. CLT Leader/Production (1).

Central to this notion of social learning within the CLT is the connectivity between "you" (individual) and "us" (community/collective) and for that connection to develop, arguably there needs to be a "common purpose." As argued by Wenger (2000) there needs to be "close tension" for learning to take place which, at individual identity level, means some alignment or commonality in values and identity but with enough "tension" or difference to trigger change. This alignment process between the "you" and "us" came through when interviewees discussed how they experienced CLT, where home life, past-experiences and work life all became interconnected:
I wouldn't describe myself as carbon literate. I would have liked to have described myself as aware of endeavouring to have a sustainable life in that I recycle at home but it didn't really bring it into work until the carbon literacy training. Production Creative (1).

I've got kids myself so I've got to think of where they're going and how they are going to get on in the future. If I can do something to help them, then it's my responsibility to do it... We all need to work together, I think, and we all know that we need to have that responsibility and take it. Production Technical (3).

Reflection on different experiences within the CLT group are crucial to social learning at a group level. The reflection process at individual and group level is triggered by differences in experience and practice within the group (Wals 2010; Keen et al. 2005). This reflection process provides space to enable conversation (Habermas 1984; O'Donnell et al. 2003; Benn and Martin 2010) and negotiation and collaboration (Keen et al. 2005), particularly where differing interests exist (Keen et al. 2005).

The CLT boundary spanning practice is designed with experience and action as central to the course. This provided the points of reflection and conversation about past experiences and knowledge at both individual and group level:

It's the difference between learning about climate change as a subject and actually learning about it as something you are going to get involved in and do, and it actually requires you to do. CLT Leader/ Production (1)

CLT is designed to bring people together with a common purpose (Coronation Street, Carbon Literacy) but from across departments. By doing so it created space to discuss the different interests, experiences and competences, to create a "boundary spanning practice" (Wenger 2000). The strength of this exploration through peer-to-peer learning came through in the interviews, hence suggesting the CLT was successful in creating a space for negotiation of meaning and collaboration (Keen et al. 2005):

Everybody participated and it was like no sort of sense of right or wrong. You were guided rather than pushed which I really enjoyed. I thought it was great to mix up people from different departments because actually I have no idea what they do on the floor because I never go down there on the production so to mix people up and get those different aspects of it. Production Creative (1).

Similarly, the common purpose led to a sense of belonging, partially through the "you" and "us" process which 
was experienced as being empowering. This suggests that the CLT evolved from a boundary spanning practice to also being a functioning CLT CoP:

I think probably the ability of everybody as a group to act together to have an impact rather than try and struggle... when everybody gets it and they have one mind, I think that's the overall feeling I got from the course. Production Technical (2).

For a successful sustained social learning within a CoP, Wenger (2000) argues that the energy levels activated within the CoP play a key role in success. Energy levels are usually reflected in the levels of "spirit of inquiry" in order to maintain interest and learn through "trial and error" in practice (Wenger 2000). The CLT program gave participants the opportunity to try new approaches, make mistakes, and challenge in a safe space (Waitoller and Kozleski 2013) by utilizing games, storytelling and role play. This seemed to spark a "spirit of inquiry" as interviews highlighted an appetite for further learning and experimentation following the course:

I could do with refreshing my.... as you would do a First Aid course. I could do with refreshing my knowledge a little bit, do a little bit more research personally. Production Technical (2).

I think it made me more aware of how we could change things in the work environment. I have changed things at home as well in (...). I've been more aware of that I suppose at home and in work as well since we did the training. Production Technical (3).

The CLT was designed to act as a trigger, or catalyst, for change through the combination of climate science with activities and experiences. There is also a strong action orientation with informants developing both personal (self) and work (us) commitments for action and change. Social learning theory suggests that successful social learning delivers changes in values and norms and a deeper understanding (Keen et al. 2005), potentially leading to transformative learning where there is disruption in the problematization of everyday events (Wals 2007):

I think for different people we are always seeking that catalytic trigger point. But it is not enough to have the trigger point unless there is a path for supported action to go on. That's why the emphasis on the low carbon culture and the carbon literacy organization is so important. CLT Leader/Production (1)

There was evidence of "catalyst effects" from the CLT in the interviews, however there were distinct differences between interviewees which seemed to hinge around identity. Those that identified themselves as "scientific" and "techie" referred to the science and the measurement toolkit as a catalytic point:
I think that, well there's an awakening, when you start seeing how big do you think the size of your carbon footprint is when you measure it because you had to measure yours. And what, you can't visualise what that actually looks like so part of the training actually showed you the size of what your carbon footprint was. Production Technical (1).

Those that identified themselves as "artistic" and "creative" tended to see the pedagogy and use of narrative as catalysts in the CLT programme:

That was one thing, the story-telling skills we have when we were doing those narratives, we could apply those. Definitely in there so it was actually in the course itself, it did lend itself. And I do think that we, I have seen a difference, I have seen a difference in people's behaviour and it has had a lasting effect on how people think. Production Creative (1).

This provides some interesting insights but also raises some further questions. All interviewees received the same course content but engaged with it and experienced it in very different ways. Transformational learning occurred, but both the catalysts and mode of participation were different, seemingly based upon individual self-identity. This confirms and extends Wenger (2000) who found that individuals experience boundaries uniquely by highlighting the role of identity in this process. The first interviewee, Production Technical (1), was participating through a technical/scientific process, through carbon measurement and evidence. The second interviewee, Production Creative (1) was participating though creating, exploring, and imagining. These ways of engaging and participating align to Wenger's modes of belonging to CoP (Wenger 2000). Both demonstrated Wenger's first mode of belonging, "engagement" however Production Technical (1) was demonstrating more of an alignment mode of belonging through scientific process, whilst Production Creative (1) was demonstrating belonging by "imagining" through the creative storytelling element (Wenger 2000). Belonging to the CLT CoP manifested differently for different people influenced by identity. This raises the question, does identity and belonging influence the translation of CLT knowledge and boundary objects into their respective CoP?

\section{Within CoP Translation of CLT Boundary Object and Within CoP Social Learning Processes}

The second stage in understanding how systems of social learning lead to change in practice is to explore how CLT knowledge (a boundary object) is translated, interpreted and re-negotiated to develop new meanings, new knowledge and new practices within, and between, the various CoPs 
(Wenger 2000; Briers and Chua 2001; Barton and Tusting 2005; Mäkitalo and Säljö 2002; Ramsten and Säljö 2012). By doing so, the researchers explored the enablers and barriers to social learning, and changes in practice at both $\mathrm{CoP}$ and organization level to assess whether identity influences this translation and learning process.

By exploring the modes of belonging within the various $\mathrm{CoP}$, insight as to what belonging means and the sense of community and common identity within the CoP is provided (Wenger 2000; O'Donnell et al. 2003) and, in turn, how this influences the learning, translation processes and development of practice. This collective identity provides insight as it embodies the values, norms and culture which shapes the participation and practice and is important in understanding the change process. The quotes demonstrate that a range of descriptions of membership emerge from the interviews with similar patterns emerging as previously (full quotes available as supplementary data table).

The two artistically orientated department heads, Production Creative (1) and Production Creative (2,) frame belonging using language to suggest imagination as a key element of the membership of the group. Both have elements of the creation of image with Production Creative 1 framing the group as story tellers, transmitting a sense of both self and group identity whilst Production Creative (2) described the group as "transformers" looking and searching for "clever solutions." Whereas the two scientific or technical production heads described membership to their CoP differently, Production Technical (3) describes his membership to his group in terms of similarity; same role, same way of thinking. This suggests a membership based on alignment, coordinating perspectives and co-ordinating ways of interpretation. Similarly, Production Technical (4) has an alignment orientation where there is change, but there is alignment collectively - "we do what we do."

Interestingly there was one exception to this pattern. Production Technical (1) is the head of a department that plays a co-ordinating role across all production departments within Coronation Street. Their description of belonging was focussed at Coronation Street level with a mix of belonging modes in their description. The team element is stressed (engagement and collaboration) alongside strong values around collaboration and equality (image of self, orientation). There were references to objects (scripts) described as an aligning boundary object within the organization and there is also reference to a "mindset" (alignment mode). It seems where purpose is organization level boundary spanning, such as in this department, a much broader notion of belonging emerges. It is argued by Wenger (2000) that these differences in modes of belonging can influence the nature and role of spirit of inquiry, sense of community and nature of practice or repertoire within $\mathrm{CoP}$ which in turn influences the social learning process of CoPs.
Social learning within the CoP takes place at the interplay between social competence (being a competent member of the group) and personal experience (Wenger 2000). The quotes used focus on how practice has changed within a particular instance as a result of knowledge and experience derived from CLT leading to the exploration of activities, objects and tools to embody that knowledge (Gherardi 2009) and socialise the activities of users (Mäkitalo and Säljö 2002).

The use of objects played a dominant role in all the interviewees' accounts of change within their CoP. Production Creative (2) talked about the creation of a storage space:

...we meticulously store all the props and dressings, we've recently invested in the storage facility and it enables us to reuse all of the props and dressings and they are used multiple times across multiple storylines and it's embedded like I've tried to change the team's approach and get them to go always first and foremost look at what we've got. Production Creative (2).

The storage space aligns to what Star and Griesemer (1989) refer to as a "repository" or an "artefact" (Wenger 2000). This became the focal point for sustainability changes within the department, a very visible tool to store props and set dressings. Practices, processes and objects have emerged within the $\mathrm{CoP}$ around the storage space which have socialised activities such as creativity in the reuse and upcycling of materials. This has resulted in the creation of a "craft corner," the creation of a new object with associated practices which reinforces the spirit of inquiry through creativity and trial and error. Within the CoP, rituals and cultures of reuse have emerged and continue to grow becoming a source of innovation within the team which is spreading to bigger projects in the show.

Production Creative (1) talks about a learning by doing approach and learning from mistakes. Their main source of feedback on success is the viewer response/ratings and therefore any changes are driven by a reflection on demographical and societal changes, and hence within this $\mathrm{CoP}$, inspiration is derived from society (outward looking to broader societal $\mathrm{CoP})$ and self (experience):

to be perfectly honest, it's because in my own life I would for instance, (...) it almost comes out of what you yourself are like if you are writing characters. Production Creative (1).

In this CoP, translation of CLT becomes embedded in the ultimate boundary object within Coronation Street (the script) and boundary object with societal CoP (the show). Learning takes place at these boundaries as to how CLT can be translated into the script. For example, to shape direction members from the $\mathrm{CoP}$ and other CoPs (executive producers, 
writers, casting, production) work together and have regular meetings. Knowledge and practice are shaped primarily by the interplay between CoPs in boundary spanning practice.

HoDs leading the technical departments talked about change very differently. Both highlighted difficulties in implementing change due to technologies that are used and the nature of activities within the CoP. Some change had occurred but within technical boundaries, learning and solutions were based upon technical competency and technical solutions (iPads, electronic scripts, halogen lights):

I thought about how we worked because it's quite difficult for us to, as a camera department to have any change directly, but prior to that we used to get, you've heard this before, scripts and obviously they were all on paper. A wad of scripts carrying them about and it's heavy, apart from obviously using paper, printing things I always used to say, can I have it in a PDF .... Production Technical (2).

the way we do things doesn't really change, we do things the same way for every single bloc. (...) whereas ours it doesn't really work that way, so it's always interesting to see what other people do compared to what we do. Production Technical (3).

\section{Between CoP Learning and Translation: Reinforcement, Ownership and Boundary Practice Infrastructures}

Interviews have highlighted how CoP elements influence the various change process within the CoPs to embed the learning from the CLT into the CoP: the spirit of inquiry, community and practice/repertoire (Wenger 2000). To understand organizational level change, and the evolution of learning and practice within a CoP, it is important to understand how further boundary practices emerge between CoPs to reinforce and further develop learning at the organization level. This involves the development of boundary practices, boundary objects and boundary spanners. In a social learning system, this enables ways of translating repertoires and enables interaction between CoP leading to higher innovation within the system (Wenger 2000). These boundary objects can grow to become boundary infrastructures (Star 2010) which reinforce social learning and practice within organizations and embody conventions and standards (Star and Ruhleder 1996). They are also influenced by the various CoP practices (Star and Ruhleder 1996).

Within the interviews, the visibility of sustainability boundary objects emerged as something that reinforced the community, culture and norms both within the CoP and at the Coronation Street level. These boundary objects were similar in that they were highly visible and spanned the whole of Coronation Street. They were "experienced" across the organization, within shared spaces, and their presence reinforced social learning processes by either triggering engagement or acting as a symbol or ritual for sustainable practice and culture.

The first visible boundary object which was valued as a major influencer was the new building (see supplementary data table). The building was highly energy efficient and had behavioural changing aspects (lights automatically turning on and off, LED lighting). These were recognised and valued by all CoPs and triggered further innovations and changes within the various communities. It was a symbol representing clean technology and practice, and of change, leading to an increased engagement, awareness and consciousness:

Yes, and it's the culture of the building, we know that everyone is quite aware of it and it is something we all think we should be responsible for. So we try and do our bit to keep it down. Support Services (1).

A second boundary object was the widespread introduction of iPads, eliminating the need for paper scripts and production plans. This organizational level boundary object was triggered by Production Creative (3) requesting the move to electronic plans and scripts. This quickly spread to other CoPs within Coronations Street and became an organizational level boundary object:

Yes, now, in my position I have to have a script reading day every few weeks, so that I can read my scripts for my next block and where we used to get them in paper format we've now started getting them as an email and PDF format so that we don't use so much paper in the reading process. Production Technical (3)

One thing I will say we are proud of, it's the iPads ... Production Creative (3).

Each department has locally adapted the use of iPads for their own needs and practices. As a result, the organization boundary practice of sharing script and show plans has changed to mainly online distribution and, again, is seem symbolically as a move towards sustainability.

The third highly visible sustainability-related boundary object was the introduction of electric cars within the production teams. Both the cars and the charging points on site featured in many interviews and were recognised as a major carbon literacy related change:

We have a production vehicle which is a Prius which is a hybrid. I drive that quite a lot and when I think about, I have been thinking about maybe getting a new car and thinking I maybe getting an electric car. Production Creative (3).

The major change now is we are all electric. All our cars are electric. Production Technical (1). 
The buyer's vehicles are now all electric hybrid vehicles, so we've replaced all of our old ones with those in the last twelve months. Production Creative (2).

The electric cars had also triggered individual level engagement, conversation and evaluation, evidence of transformational learning and the "double knit process" (McDermott 1999). Several of the interviewees considered the option of purchasing an electric car for personal use (personal adoption).

A fourth highly visible sustainability-related boundary object was the "ALBERT" which is a BAFTA certification for TV production incorporating a carbon calculator. This has created a sense of pride and alignment of identities within Coronation Street towards CLT and increased the sense of belonging. It can therefore be argued that this is a visionary boundary object which evokes positive emotional responses and has high levels of legitimacy across the organization (Briers and Chua 2001). Associated boundary objects, such as ALBERT forms, are completed at the end of each shoot to collect the carbon footprint information from each production unit embedding the practice of measuring and monitoring within CoPs and reinforcing CLT learning:

...here's an ALBERT form... in and we still do that every month. Production Technical (4).

When we go the ALBERT, the sustainable thing, I think we were very proud. I think there was a real sense of pride that, yes actually we have done a good thing. Production Creative (1).

These very visible boundary objects have developed into an infrastructure of boundary objects and associated practice at organization level which reinforces sustainability practice within CoP. Interestingly, there were similar patterns of engagement with these broader boundary objects to the CLT. The creatives tended to engage in an imagining mode (symbolism, hope, change, challenge and identity) whilst the technical CoP engaged in an alignment way (technical solutions, alignment and measurement). This highlights the consistency in patterns of engagement with boundary practices and objects by identity types.

Boundary spanners also featured strongly in the interviews as an influencing factor in the translation process. Boundary spanners are people who love connections between groups and actively cross boundaries as members of multiple groups and CoP (Akkerman and Bakker 2011a; Wenger 2000). Boundary spanners play the role of translators and import and export knowledge and practices between CoP (Waitoller and Kozleski 2013) mainly through the creation of dialogue (Akkerman et al. 2006).

Within the interviews a clear boundary spanner emerged, featuring in all interviews as an influencer/ supporter/pioneer both during and after CLT. The boundary spanner collaborated in the development of the CLT curriculum and enabled "buy in" both at the management level (ITV and Coronation Street) and at CoP level (see supplementary data table). Within the interviews the boundary spanner acknowledged and reflected on their role:

...that was very much about internal brokering, relationships, working with procurement, working with CSR team, working with finance guys, working with marketing we had a logo, we've got the green ducks at the end. CLT Leader/Production (2).

The boundary spanner was conscious of both his identity and role as a boundary spanner. He acknowledged his part in importing and exporting knowledge as well as the boundaries of that role:

What I was clear about when I was doing these meetings was I didn't want to be the green guy. Apart from anything else it wasn't actually my main job CLT Leader/Production (2)

The role was not the "doer" or "executer," they saw themself as an enabler, a motivator, as somebody who could import and translate CLT knowledge and resources into different CoPs. By combining technical and artistic aspects in their own role, they could use different translation strategies and approaches.

The boundary spanner worked with all the CoPs in Coronation Street and featured in every research interview either as a catalyst, motivator or enabler. They also took on the 'challenge' role, using conversation to enable problem solving, engagement and experience within the various CoPs, and translated and adapted knowledge relative to each of the CoP needs, challenges and competences.

\section{The Storyline as the Ultimate Boundary Object in the CLT Story}

Successful social learning can lead to multiple loop learning resulting in changing norms, values and a deeper learning understanding (Keen et al. 2005; McDermott 1999). Transformative learning involves the disruption of the problematization of everyday events (Wals 2010) where mental models are reorganized to process information (Argyris and Schon 1996). When such a change has taken place, it becomes deep rooted in the mindset and decision processes of individuals and CoPs.

Interviewees responded unanimously when asked about how sustainability and carbon literacy features in the activities and decision making within the CoP. According to the responses it had become deeply rooted, or "second nature," 
within the decision making and problem-solving processes (see supplementary data table). This was irrespective of identity and orientation, regardless of differences in modes of belonging and processes. CLT had become second nature:

I think it is now just embedded. Production Techni$\operatorname{cal}(1)$

I think a gradual, cultural change, yes, I do. Production Creative (2)

I think we are all aware that's the norm...... it's something we naturally do as we are going along.

Support Services (1)

This has been aided by the clear common focus across the Coronation Street: the continuing storyline is the ultimate purpose. It aligns all $\mathrm{CoP}$ processes and practices across the organization acting as the ultimate boundary spanning object. The story acts simultaneously as an artefact (tools, documents and models), a discourse (common language and negotiation) and routines and procedures which coordinates multiple boundary practices.

CoPs participate, learn from and contribute to formal boundary practices associated with the development of the storyline (script meetings, storyline conference, production meetings) alongside many informal boundary practices which have emerged between production, producers, editorial and design. A boundary object closely aligned with the storyline is the script which acts as a plan for the various $\mathrm{CoP}$, and $\mathrm{CoPs}$ are enabled to feed into storylines:

...like to work with [name] who is a producer and the writers on this, so we've done tours and I've talked through ideas with them and kind of got their input and made sure, I don't want to do things which they are not going to use onscreen. Production Creative (2)

I think (the decision on storyline ideas) that would come down to the producer. (...) but the great thing as we are at the moment and [person] our producer at the moment is a good idea can come from anywhere. And we, anybody on the show, if they have a good idea she would consider it, which is great. Production Creative (1)

The production of the show (creating the storyline, writing the storyline, production) creates a space for dialogue, negotiation and problem solving. This space at organizational level enables the exploration of new ideas, reflection on current practice and the development of new patterns of thinking and acting (O'Donnell et al. 2003). The resulting script acts as guidance to the CoPs but creative space is given as to how this knowledge is translated, adapted and modified within the CoP. This creates the essential balance between organizational support and space (Wenger 1998) and enables the creation of tacit knowledge but also develops sensory and aesthetic pathways for creativity (Gherardi 2009).

CLT initially was focussed on the greening of the production side of Coronation Street, the "behind the scenes" internally focussed practices. However, the CLT training also triggered reflection on how sustainability featured in the "public face" of Coronation Street, i.e. the show:

So the reason I think Corrie is really, really special for this work because we realise and this was in the slide deck that we can influence the way we make the show and try and reduce the carbon impact of production process in getting the show to air. But it would have been remiss of us and a shame if we hadn't realised the fact it has an audience of 7.9 million people. CLT Leader/Production (2)

Coronation Street, and in particular the CLT participants, realised that by embedding sustainability within the show they could create a wider social learning process with their viewing community. The show is the ultimate Coronation Street boundary object with the viewing public. However, embedding sustainability into the show is not without challenges and is a social learning process in itself through engagement and trial and error:

...it's a very, very fine line, it really is a fine line with it, you are talking here on our show and I think it's true on all the soaps as well, the audience are very resistant to change. If we bring a new character in it takes about a year to bed them in, if we bring a new family in it takes at least two years. CLT Leader/ Production (2).

...I think we do have to be careful (...) it is this thing about leading people not pushing them into it. We did many, many years ago did do a story which was specifically recycling with a thing like that and interestingly it didn't go down very well with the audience. Production Creative (1).

This cautiousness arises from the relationship between the viewing community and the boundary object (the show). The show needs to deliver on entertainment factors to keep viewers engaged:

...they invite us into their homes and so they don't expect us to tell them what to do. Now if we are showing that these characters do this and they don't mind that, but the minute we try telling people what to do you get that resistance. Production Creative (1).

....at the end of the day we are a drama not a documentary...Because it's a very, very fine line, it really is a fine line with it, you are talking here on our show 
and I think it's true on all the others. Production Creative (1).

A trial and error approach led to learning within Coronation Street in terms of how sustainability content is experienced and engaged with by audience members. This has resulted in a number of subtle innovations to embed sustainability into the program. This need for subtlety became a creative challenge for some groups within the program:

I think we did do something when we brought the charging in for the bags, when that fee the $5 p$ fee, we did a little thing, not a massive story but we did something on screen to bolster the message that the law had come in. So we would do things like that. Production Creative (1).

Through the analysis and exploration of the case study's two overarching research questions, patterns emerged in both the impact of the CLT on individual and CLT group and in the translation process into CoP knowledge and practice. These patterns are further explored in a conceptualization of findings.

\section{Conceptualization of Findings}

The analysis highlights that the CLT experience, and subsequent social learning process, was influenced by the selfidentity of participants. Transformative social learning occurred as a result of the CLT as there was a change in the problematization of everyday events (Wals 2010) and mental models were reshaped to take into account new information (Argyris and Schon 1996). This was enabled by a diverse cohort across departments and a pedagogy aligned to the culture and "ways of doing" within the organization. This pedagogy consisted of games, storytelling and problem solving, which created space for the process of reflection, discussion and group problem solving (Wals 2007).

Certain individual level factors influenced this CLT social learning process. Prior sustainability experience and knowledge partially influenced the attitude and value placed upon the CLT, however self-identity was a major influence on the mode of engagement, experience and the nature of the transformational learning catalyst, concurring with Warr Pedersen (2017). He found that personal values and professional identity were the two driving factors for engagement in peer learning. It is also important to note that identity was not static and through the transformative learning process the notions of "self-identity" and "climate self" were also influenced by the CLT training.

The second stage translation process into $\mathrm{CoP}$ group practice was influenced directly by the mode of belonging within the CoP (Wenger 2000). This was through the influence of belonging and the experience of the group membership and interactions with "within group" and "outside group" practices and objects. Of central importance to this process was the creation of space as an enabler to this translation process both within and between CoP. This space enabled communicative reasoning in order to develop and negotiate meaning and new patterns of thinking and acting (O'Donnell et al. 2003). This "creative" and "discursive" space was important for the translation and innovation process to create self-organized and locally-owned practice. There were two interactions evident in the translation process. First, identity influenced how change was viewed (as a challenge for creativity or bounded by technology) and how boundary objects were engaged with. This is because identity has a direct influence on the nature of belonging which in turn influenced group experiences, social learning processes and engagement. Secondly, space and creative identity had a strong interaction leading to creativity and innovation.

Boundary practices, objects and spanners played a key role in the adaption, innovation and embedding process. The organization boundary infrastructure reinforced both CLT learning and the translation of knowledge into social learning practices within CoPs by embodying conventions, norms and standards (Star and Ruhleder 1996). Once again, how they were experienced was shaped by identity. The organization boundary infrastructure was also essential in the provision of space within the social learning system by providing guidance and organizational support whilst enabling creative space for discussion and creation of meaning at the local level (O'Donnell et al. 2003). This was particularly true with the "ultimate" boundary object, the script, which was a guide to all the CoP but was also directly influenced by $\mathrm{CoP}$ activities and practice.

\section{Conclusion}

Responsible management involves the embedding of sustainability, responsibility and ethics into the practices of all managers (Laasch and Conaway 2015). This study, using the communities of practice and social learning lens, has traced how CLT influenced individual managers and also how the sustainability knowledge and experience gained from the training became translated and embedded into group practice and decisions, resulting in a reduction in greenhouse gas emissions at Coronation Street.

In addressing the first research question, how CLT influenced social learning at an individual and group level, four key design features led to the success of the program at the individual level. The first feature was the combination of science and facts, with experiences, dialogue and games to enable participants to "trial and error," creating a safe discursive space to share experiences across boundaries (Waitoller 
and Kozleski 2013). The second was the alignment of the pedagogy to the culture of the TV sector and organization. By using a trainer who knew the TV sector well, in addition to role play, storytelling and narratives, the course aligned to creative "ways of working" enabling participants to be relaxed and receptive. This reinforced the feeling of CLT as a safe place to discuss, negotiate and create shared meaning (Keen et al. 2005). Third was the process of connecting "me" and "we." This engaged individual identity and experience to bring widespread transformational change enabling it to take place both in and outside the workplace by creating close tension and exploration of values and identity (Wenger 2000). This also started the process of building a collective sense of identity and belonging (Wenger 2000) which enabled CLT CoP development and a collective purpose. Fourth, by linking learning to individual and group pledges for action post course, the link to change in practice in the workplace was made explicit.

At the group level, the social learning was greatly enhanced by the creation of focussed courses (production, editorial and leadership) which gave a sense of shared purpose but at the same time consisted of diverse cohort members from across the organization. This led to a divergent range of norms, interests, competences, values and experiences which enhanced the social learning experience (Wals 2010, 2007; Keen et al. 2005). This also reinforced the "close tension" (Wenger 2000) created by the "me" and "we" alignment and reinforced the texture of practice. The diverse cohort also strengthened the impact of dialogue and conversational space (Habermas 1984; O'Donnell et al. 2003; Benn et al. 2013) and negotiation and collaboration (Keen et al. 2005). An interesting feature that emerged from the analysis was the role of self-identity in shaping both how the CLT course was experienced and the nature of catalyst/ trigger for transformational learning. Those who identified as artistic were triggered by the pedagogy whilst those that identified as scientific were triggered by the science and measurement tools. This pattern of difference consistently featured throughout the study and shaped the differences in terms of group belonging, nature of social learning and change, the translation process and engagement with boundary objects. This has implications for the design of social learning programs within the workplace when a wide range of identities and orientations are present.

Turning to the second question it was also found that identity and modes of belonging to the CoP shaped the modes of social learning and translation within the CoP. Those with a creative orientation used "imagination" style language to describe both membership and change within the group whereas the more technical scientific groups use the language of alignment and technology was a dominant object within the change process.
The use of artefacts and objects featured quite strongly in the change and learning process with a combination of importing of boundary objects and processes with the introduction and creation of new ones. These objects embodied the evolving sustainability knowledge within the CoP and were key in"opening and expanding a discursive space" (Benn and Martin 2010, p. 405). This in turn led to a negotiation of locally relevant and valuable meaning (Keen et al. 2005) and embedding in "in situ" practice (Price et al. 2019; Gherardi 2019). This space also led to the exploration of new ideas and reflection on current practice and new ways of thinking (O'Donnell et al. 2003) with a sustained "spirit of inquiry" within the CoP (Wenger 2000). In general, changes in norms, values and culture within the CoP arose from the use of objects and practices in order to change and socialise behaviour within groups (O'Donnell et al. 2003) leading to collective "knowing in practice" (Price et al. 2019; Gherardi 2019).

Boundary objects, boundary practices and boundary spanners also featured very strongly in the social learning and change process. A number of different practices and objects emerged at the Coronation Street level which reinforced both the CLT CoP but also created the space for continued social learning and practice change within the various CoP (Akkerman and Bakker 2011b). These practices and objects created a system or infrastructure which embodied conventions and standards in Coronation Street (Star and Ruhleder 1996) and was key in the creation of space at CoP level. The infrastructure enabled the creative space for $\mathrm{CoP}$ to locally develop and evolve their "own way of doing" with the infrastructure being the "guiding mechanism." In this respect, the role of the boundary spanner was particularly important as they acted as a challenger, negotiator, translator (Waitoller and Kozleski 2013) and importer and exporter of knowledge (Karen and Bush 2010). The evolution of the boundary infrastructure enabled the sustainability-related boundary practices and objects to grow in agency within Coronation Street as a result of interconnections in objects, people and practice (Price et al. 2019; Gherardi 2019; Pelling et al. 2008) and social learning evolved with new negotiated meaning between and within CoP. As a result, sustainability became more embedded in practice, in situ, in locally relevant and meaningful ways (Price et al. 2019; Gherardi 2019).

An interesting feature of the boundary infrastructure was the role of the show itself. The show is the main purpose and identity of Coronation Street at organization level. As an object it embodies the knowledge, values, culture and identity of the program. Within the infrastructure it fulfils a number of roles: an artefact (tools, documents and models), a discourse (common language and negotiation) and routines and procedures, which coordinates multiple boundary practices. There are a number 
of boundary spanning practices associated with the show which provides CoP guidance from, but is also shaped by, contributions from the CoP. Initially CLT and sustainability practice was focussed on the production side of Coronation Street, however as sustainability became more embedded in practice, the show started to include sustainability issues in the storyline, where the show is learning by trial and error as to how to embed sustainability within the storyline, drawing inspiration from societal best practices. The show is essentially mirroring and learning from society at the ultimate boundary.

Acknowledgements We would like to thank ITV productions and the Coronation Street team for their ongoing support and all the interviewees for their time and contribution to this project.

\section{Compliance with Ethical Standards}

Conflict of interest The authors declare that they have no conflict of interest.

Open Access This article is distributed under the terms of the Creative Commons Attribution 4.0 International License (http://creativeco mmons.org/licenses/by/4.0/), which permits unrestricted use, distribution, and reproduction in any medium, provided you give appropriate credit to the original author(s) and the source, provide a link to the Creative Commons license, and indicate if changes were made.

\section{References}

Ackoff, R. L., \& Greenberg, D. (2008). Turning learning right side up: Putting education back on track. Englewood Cliffs, NJ: Pearson Prentice Hall.

Akkerman, S., Admiraal, W., Simons, R. J., \& Niessen, T. (2006). Considering diversity: Multivoicedness in international academic collaboration. Culture \& Psychology, 12(4), 461-485.

Akkerman, S. F., \& Bakker, A. (2011a). Boundary crossing and boundary objects. Review of Educational Research, 81(2), 132-169.

Akkerman, S. F., \& Bakker, A. (2011b). Learning at the boundary: An introduction. International Journal of Educational Research, 50(1), 1-5.

Argyris, C., \& Schon, D. A. (1996). Organizational learning II: Theory, method and practice. Reading, MA: Addison-Wesley.

BAFTA, Albert. (2017). Sustainable film and TV production training'Albert' via BAFTA. Retrieved January 05, 2018, from http://weare albert.org/help/get-trained.

Bandura, A. (1978). Social learning theory of aggression. Journal of communication, 28(3), 12-29.

BARB. (2018). Broadcasters' Audience Research Board. Retrieved January 05, 2018, from https://www.barb.co.uk/.

Barton, D., \& Tusting, K. (Eds.). (2005). Beyond communities of practice: Language power and social context. Cambridge: Cambridge University Press.

Bateson, G. (2000). Steps to an ecology of mind: Collected essays in anthropology, psychiatry, evolution, and epistemology. Chicago: University of Chicago Press.

BBC. (2010). Retrieved March 25, 2018, from http://www.bbc.co.uk/ news/av/entertainment-arts-11410873/coronation-street-recog nised-as-longest-running-soap.
Benn, S., Edwards, M., \& Angus-Leppan, T. (2013). Organizational learning and the sustainability community of practice: The role of boundary objects. Organization \& Environment, 26(2), 184-202.

Benn, S., \& Martin, A. (2010). Learning and change for sustainability reconsidered: A role for boundary objects. Academy of Management Learning \& Education, 9(3), 397-412.

Bowker, G. C., \& Star, S. L. (2000). Sorting things out: Classification and its consequences. Cambridge: MIT Press.

Briers, M., \& Chua, W. F. (2001). The role of actor-networks and boundary objects in management accounting change: A field study of an implementation of activity-based costing. Accounting, Organizations and Society, 26(3), 237-269.

Carbon Literacy Certificate. (2017). Retrieved January 05, 2018, from http://www.carbonliteracy.com/individual/.

Carbon Literacy Project. (2011). www.carbonliteracy.com

Carbon Literacy Standard. (2016). http://www.carbonliteracy.com/wpcontent/uploads/2016/12/3.-Executive-Summary-of-The-Carbo n-Literacy-Standard-v1.06.pdf

Coldren, A., \& Spillane, J. P. (2007). Making connections to teaching practice: The role of boundary practices in instructional leadership. Educational Policy, 21(2), 369-396.

Cooler Projects CIC. (2011). http://www.coolerprojects.com/about/

Cornuel, E., \& Hommel, U. (2015a). Moving beyond the rhetoric of responsible management education. Journal of Management Development, 34(1), 2-15.

Cornuel, E., \& Hommel, U. (2015b). Moving beyond the rhetoric of responsible management education. Journal of Management Development, 34(1), 2-15.

Cunliffe, A. L. (2009). The philosopher leader: On relationalism, ethics and reflexivity - a critical perspective to teaching leadership. Management Learning, 40(1), 87-101.

Dubois, A., \& Gadde, L. E. (2002). Systematic combining: An abductive approach to case research. Journal of Business Research, 55(7), 553-560.

Dyball, R., Brown, V. A., \& Keen, M. (2007). Towards sustainability: Five strands of social learning. In A. E. J. Wals (Ed.), Social learning towards a sustainable world (pp. 181-194). Wageningen Academic Publishers: Wageningen.

Dyllick, T. (2015). Responsible management education for a sustainable world: The challenges for business schools. Journal of Management Development, 34(1), 16-33.

Elkjaer, B. (2001). The learning organization: An undelivered promise. Management learning, 32(4), 437-452.

Engeström, Y., Engeström, R., \& Kärkkäinen, M. (1995). Polycontextuality and boundary crossing in expert cognition: Learning and problem solving in complex work activities. Learning and Instruction, 5, 319-336.

Gherardi, S. (2006). Organizational Knowledge: The texture of workplace learning. Oxford: Blackwell Publishing.

Gherardi, S. (2009). Community of practice or practices of a community. In S. J. Armstrong \& C. V. Fukami (Eds.), The Sage handbook of management learning, education, and development (pp. 514-530). London: Sage.

Gherardi, S. (2019). How to conduct a practice-based study: Problems and methods (2nd ed.). Cheltenham: Edward Elgar.

Gherardi, S., \& Strati, A. (2012). Learning and knowing in practicebased studies. Cheltenham: Edward Elgar.

Gioia, D. (2012). Seeking qualitative rigour in inductive research: Notes on the Gioia methodology organisational research methods. Sage Journal. https://doi.org/10.1177/1094428112452151.

Gioia, D. A., \& Chittipeddi, K. (1991). Sensemaking and sensegiving in strategic change initiation. Strategic Management Journal, 12(6), 433-448

Gioia, D. A., Corley, K. G., \& Hamilton, A. L. (2013). Seeking qualitative rigor in inductive research: Notes on the Gioia methodology. Organizational Research Methods, 16(1), 15-31. 
Glasser, H. (2007). Minding the gap: The role of social learning in linking our stated desire for a more sustainable world to our everyday actions and policies. Social learning towards a sustainable world (pp. 35-62). Wageningen: Wageningen Academic Publishers.

Green, M. F. (2011). Lost in translation: Degree definition and quality in a globalized world. Change, 43(5), 18-27.

Habermas, J. (1984). The theory of communicative action volume 1: Reason and the rationalization of society. London: Heinemann.

Hardy, C., Lawrence, T. B., \& Grant, D. (2005). Discourse and collaboration: The role of conversations and collective identity. Academy of Management Review, 30(1), 58-77.

Haugh, H., \& Talwar, A. (2010). How do corporations embed sustainability across the organization? Academy of Management Learning and Education, 9(3), 384-396.

Hibbert, P., \& Cunliffe, A. (2015). Responsible management: Engaging moral reflexive practice through threshold concepts. Journal of Business Ethics, 127(1), 177-188.

Järvensivu, T., \& Törnroos, J. A. (2010). Case study research with moderate constructionism: Conceptualization and practical illustration. Industrial Marketing Management, 39(1), 100-108.

Karen, P. I., \& Bush, S. R. (2010). Educating students to cross boundaries between disciplines and cultures and between theory and practice. International Journal of Sustainability in Higher Education, 11(1), 19-35.

Keen, M., Brown, V. A., \& Dyball, R. (Eds.). (2005). Social learning in environmental management: Towards a sustainable future. London: Routledge.

Kirkeby, O. F. (1990). Abduktion. In Andersen, H. (Ed.), Vetenskapsteori och metodla"ra. Introduktion, (Liungman, C. G., Trans.). Lund: Studentlitteratur.

Laasch, O., \& Conaway, R. (2015). Principles of responsible management: Glocal sustainability, responsibility, ethics. Stamford, CT: Cengage.

Laasch, O. \& Gherardi, S. (2019) Delineating and reconnecting responsible management, learning, and education (RMLE): A research agenda through a social practice lens. Paper presented at the Academy of Management Conference, Boston.

Langley, A. (1999). Strategies for theorizing from process data. Academy of Management Review, 24(4), 691-710.

Lave, J., \& Wenger, E. (1991). Situated learning: Legitimate peripheral participation. Cambridge: Cambridge University Press.

Levina, N., \& Vaast, E. (2005). The emergence of boundary spanning competence in practice: Implications for implementation and use of information systems. MIS quarterly, 29, 335-363.

Lincoln, Y. S., Lynham, S. A., \& Guba, E. G. (2011). Paradigmatic controversies, contradictions, and emerging confluences, revisited. In N. K. Denzin \& Y. S. Lincoin (Eds.), The Sage handbook of qualitative research (Vol. 4, pp. 97-128). London: Sage.

Locke, K., \& Golden-Biddle, K. (1997). Constructing opportunities for contribution: Structuring intertextual coherence and "problematizing" in organizational studies. Academy of Management Journal, 40(5), 1023-1062.

Lucas, L. M., \& Ogilvie, D. T. (2006). Things are not always what they seem: How reputations, culture, and incentives influence knowledge transfer. The Learning Organization, 13(1), 7-24.

Mäkitalo, Å., \& Säljö, R. (2002). Invisible people. Institutional reasoning and reflexivity in the production of services and 'social facts' in public employment agencies. Mind, Culture, and Activity, 9(3), 160-178.

Manchester Evening News. (2015). Retrieved March 25, 2018, from https://www.manchestereveningnews.co.uk/whats-on/film-and-tv/ coronation-street-named-tvs-greenest-9577170.

McCright, A. M., Dunlap, R. E., \& Marquart-Pyatt, S. T. (2016). Political ideology and views about climate change in the European
Union. Environmental Politics, 25(2), 338-358. https://doi. org/10.1080/09644016.2015.1090371.

McDermott, R. (1999). Learning across teams. Knowledge Management Review, 8(3), 32-36.

McNamara, C. (2009). General guidelines for conducting interviews. Retrieved January 27, 2019, from http://managementhelp.org/ evaluatn/intrview.htm

Meyer, C. B. (2001). A case in case study methodology. Field methods, 13(4), 329-352.

Millar, J., \& Price, M. (2018). Imagining management education: A critique of the contribution of the united nations PRME to critical reflexivity and rethinking management education. Management Learning. https://doi.org/10.1177/1350507618759828.

Muff, K., Dyllick, T., Drewell, M., North, J., Shrivastava, P., \& Haertle, J. (2013). Management education for the world: A vision for business schools serving people and the planet. Cheltenham: Edward Elgar Publishing.

O’Donnell, D., Porter, G., McGuire, D., Garavan, T. N., Heffernan, M., \& Cleary, P. (2003). Creating intellectual capital: A Habermasian community of practice $(\mathrm{CoP})$ introduction. Journal of European Industrial Training, 27(2), 80-87.

Peirce, C. S. (1931-1935). The collected papers of Charles S. Peirce (Vol. 8). Cambridge: Harvard University Press.

Pelling, M., \& High, C. (2005). Understanding adaptation: What can social capital offer assessments of adaptive capacity? Global environmental change, 15(4), 308-319.

Pelling, M., High, C., Dearing, J., \& Smith, D. (2008). Shadow spaces for social learning: A relational understanding of adaptive capacity to climate change within organisations. Environment and Planning A, 40(4), 867-884.

Pless, N. M., Maak, T., \& Stahl, G. K. (2011). Developing responsible global leaders through international service-learning programs: The ulysses experience. Academy of Management Learning and Education, 10(2), 237-260.

Pratt, M. G. (2008). Fitting oval pegs into round holes: Tensions in evaluating and publishing qualitative research in top-tier North American journals. Organizational Research Methods, 11(3), 481-509.

Price, O., Gherardi, S., \& Manidis, M. (2019). Enacting responsible management: A practice based perspective. In O. Laasch, D. Jamali, E. Freeman, \& R. Suddaby (Eds.), The research handbook of responsible management. Cheltenham: Edward Elgar.

Ramsten, A. C., \& Säljö, R. (2012). Communities, boundary practices and incentives for knowledge sharing?: A study of the deployment of a digital control system in a process industry as a learning activity. Learning, Culture and Social Interaction, 1(1), 33-44.

Rasche, A., \& Gilbert, D. U. (2015). Decoupling responsible management education: Why business schools may not walk their talk. Journal of Management Inquiry, 24(3), 239-252.

Sandelowski, M. (2010). What's in a name? Qualitative description revisited. Research in Nursing \& Health, 33(1), 77-84.

Shrivastava, P. (2010). Pedagogy of passion for sustainability. Academy of Management Learning and Education, 9(3), 443-455.

Siggelkow, N. (2007). Persuasion with case studies. Academy of Management Journal, 50(1), 20-24.

Smith, S., Kempster, S., \& Wenger-Trayner, E. (2018). Developing a program community of practice for leadership development. Journal of Management Education. https://doi.org/10.1177/10525 62918812143.

Solitander, N., Fougere, M., Sobczak, A., \& Herlin, H. (2012). We are the champions: Organizational learning and change for responsible management education. Journal of Management Education, 36(3), 337-363. 
Spens, K. M., \& Kovács, G. (2006). A content analysis of research approaches in logistics research. International Journal of Physical Distribution \& Logistics Management, 36(5), 374-390.

Star, S. L. (2010). This is not a boundary object: Reflections on the origin of a concept. Science, Technology and Human Values, 35(5), 601-617.

Star, S. L., \& Griesemer, J. R. (1989). Institutional ecology, translations' and boundary objects: amateurs and professionals in Berkeley's Museum of Vertebrate Zoology, 1907-39. Social Studies of Science, 19(3), 387-420.

Star, S. L., \& Ruhleder, K. (1996). Steps toward an ecology of infrastructure: Design and access for large information spaces. Information systems research, 7(1), 111-134.

Strauss, A., \& Corbin, J. (1998). Basics of qualitative research: Techniques and procedures for developing grounded theory. Thousand Oaks, CA: Sage Publications Inc.

Tracy, S. J. (2010). Qualitative quality: Eight "big-tent" criteria for excellent qualitative research. Qualitative inquiry, 16(10), 837-851.

Waitoller, F. R., \& Kozleski, E. B. (2013). Working in boundary practices: Identity development and learning in partnerships for inclusive education. Teaching and Teacher Education, 31, 35-45.

Wals, A. E. (2007). Social learning towards a sustainable world: Principles, perspectives, and praxis. Academic Pub: Wageningen.

Wals, A. E. (2010). Mirroring, Gestaltswitching and transformative social learning: Stepping stones for developing sustainability competence. International Journal of Sustainability in Higher Education, 11(4), 380-390.

Warr Pedersen, K. (2017). Supporting collaborative and continuing professional development in education for sustainability through a communities of practice approach. International Journal of Sustainability in Higher Education, 18(5), 681-696.

Wenger, E. (1998). Communities of practice: Learning as a social system. Systems thinker, 9(5), 2-3.

Wenger, E. (2000). Communities of practice and social learning systems. Organization, 7(2), 225-246.

Wenger, E. (2010). Communities of practice and social learning systems: The career of a concept. In C. Blackmore (Ed.), Social learning systems and communities of practice (pp. 179-198). London: Springer.

Williams, P. (2002). The competent boundary spanner. Public Administration, 80(1), 103-124.

Woodward, J. (1989). Data and phenomena. Synthese, 79, 393-472.

Yin, R. K. (2018). Case study research and applications: Design and methods (6th ed.). Thousand Oaks, CA: Sage.

Publisher's Note Springer Nature remains neutral with regard to jurisdictional claims in published maps and institutional affiliations. 